\title{
Glycerol fructose combined with vitamin B6 is beneficial to postoperative recovery of patients with cerebral aneurysm
}

\author{
XIYA CHEN $^{1}$ and TING LEI ${ }^{2}$ \\ ${ }^{1}$ Department of Neurosurgery, The Central Hospital of Wuhan, Tongji Medical College, Huazhong University \\ of Science and Technology, Wuhan, Hubei 431400; ${ }^{2}$ Department of Neurosurgery, Tongji Hospital, Tongji \\ Medical College, Huazhong University of Science and Technology, Wuhan, Hubei 430000, P.R. China
}

Received January 24, 2018; Accepted March 23, 2018

DOI: $10.3892 / \mathrm{etm} .2018 .6133$

\begin{abstract}
The aim of the present study is to investigate whether glycerol fructose combined with vitamin B6 is beneficial to the postoperative recovery of patients with cerebral aneurysm (CA). A total of 134 patients receiving embolization of $\mathrm{CA}$ in the Central Hospital of Wuhan between February, 2013 and June, 2015 and were divided into observation and control groups according to the random number table method, with 67 cases in each group. The control was given vitamin B6 routine treatment, while the observation group received glycerol fructose on the basis of treatment in the control group. The incidence rate of postoperative complications after treatment, Glasgow coma scale (GCS) score, Barthel index score, and neurological fatigue index (NFI) score were compared between the two groups. After treatment, the GCS, Barthel index and NFI scores of patients in the observation were better than those in the control group $(\mathrm{p}<0.05)$, and the Barthel index score in the observation group was significantly higher than that in the control group $(\mathrm{p}<0.01)$. The mean flow velocity of middle cerebral artery (MCA) in the observation group after treatment was significantly different from that in the control group $(\mathrm{p}<0.05)$. As for complications, the incidence rates of postoperative cerebral vasospasm $(1.49 \%)$, cerebral ischemia $(1.49 \%)$, hematoma at puncture site $(2.98 \%)$ and aneurysm rupture and hemorrhage $(4.47 \%)$ in the observation group were lower than those of cerebral vasospasm $(8.95 \%)$, cerebral ischemia (7.46\%), hematoma at puncture site $(8.95 \%)$ and aneurysm rupture and hemorrhage $(10.44 \%)$ in the control group, and the differences were statistically significant $(\mathrm{p}<0.05)$. In conclusion, glycerol fructose combined with vitamin B6 can reduce the incidence rate of postoperative complications and improve patients' self-care ability and quality of life. Therefore,
\end{abstract}

Correspondence to: Dr Ting Lei, Department of Neurosurgery, Tongji Hospital, Tongji Medical College, Huazhong University of Science and Technology, 1095 Jiefang Avenue, Wuhan, Hubei 430000, P.R. China

E-mail: tzy8vj@163.com

Key words: glycerol fructose, vitamin B6, cerebral aneurysm, cerebral vasospasm, postoperative complications it is beneficial to postoperative recovery and it is worthy of clinical application.

\section{Introduction}

Cerebral aneurysm (CA) is a kind of common cerebrovascular disease mostly affecting the elderly population. Previous findings have shown that CA ranks third in cerebrovascular diseases, and that the mortality rate of patients is on the increase currently, posing a serious threat to health and safety (1-3). The main danger comes from the subarachnoid hemorrhage and intracranial hemorrhage caused by the rupture of the aneurysm (4). At present, embolization is the main treatment for $\mathrm{CA}$, which is fast and effective to control local hemorrhage and improve the prognosis of patients. However, postoperative complications such as cerebral vasospasm, cerebral ischemia, hematoma at puncture site, and aneurysm rupture and hemorrhage may easily lead to death and disability (5-7).

In recent years, the effects of hyperbaric oxygen and nimodipine in the treatment of postoperative complications of CA have not been good. Glycerol fructose, as a new compound preparation, is composed of fructose, glycerin and sodium chloride. It can effectively increase plasma osmotic pressure, thereby causing dehydration to reduce intracranial pressure, and it has a long duration and low side effects. Thus, it can reduce the incidence rate of postoperative complications in patients with CA (8). Vitamin B6, as a member of the vitamin B family, can regulate glycogen metabolism, participate in the transformation of unsaturated fatty acids and the synthesis of neural medium, and improve the postoperative mental state of patients (9). However, there is a lack of related randomized controlled trials in clinical practice. Therefore, this study aimed to investigate glycerol fructose and vitamin B6 in the postoperative recovery of patients with $\mathrm{CA}$, in order to provide a reference for clinical practice.

\section{Materials and methods}

Patient information. A total of 134 patients undergoing embolization of CA from February, 2013 to June, 2015 in the Central Hospital of Wuhan (Wuhan, China) were divided into the observation $(n=67)$ and control $(n=67)$ groups according to random number table method. The observation group 
Table I. Clinical information data of patients.

\begin{tabular}{|c|c|c|c|c|c|}
\hline Groups & No. & Observation group & Control group & F-value & P-value \\
\hline Sex & & & & 0.524 & 0.681 \\
\hline Male & 72 & $37(55.22)$ & $35(44.78)$ & & \\
\hline Female & 62 & $30(48.39)$ & $32(51.00)$ & & \\
\hline Age (years) & & & & 0.311 & 0.795 \\
\hline$>55$ & 71 & $34(47.89)$ & $37(52.11)$ & & \\
\hline$\leq 55$ & 63 & $31(49.21)$ & $32(50.79)$ & & \\
\hline Nationality & & & & 0.541 & 0.618 \\
\hline The Han nationality & 121 & $61(50.41)$ & $60(49.59)$ & & \\
\hline Ethnic minorities & 13 & $7(53.85)$ & $6(46.15)$ & & \\
\hline Tumor type & & & & 1.976 & 0.161 \\
\hline $\begin{array}{l}\text { Anterior communicating } \\
\text { aneurysms }\end{array}$ & 32 & $15(46.88)$ & $17(53.13)$ & & \\
\hline Posterior communicating aneurysms & 45 & $24(53.33)$ & $21(46.67)$ & & \\
\hline Middle cerebral artery aneurysm & 30 & $16(53.33)$ & $14(46.67)$ & & \\
\hline Anterior cerebral artery aneurysm & 17 & $10(58.82)$ & $7(41.18)$ & & \\
\hline Vertebrobasilar aneurysm & 10 & $6(60.00)$ & $4(40.00)$ & & \\
\hline Hunt-Hess score & & & & 0.214 & 0.810 \\
\hline I & 40 & $22(55.00)$ & $18(45.00)$ & & \\
\hline II & 81 & $49(60.49)$ & $32(39.51)$ & & \\
\hline III & 13 & $7(53.85)$ & $6(46.15)$ & & \\
\hline Smoking history & & & & 1.531 & 0.091 \\
\hline Yes & 75 & $40(53.33)$ & $35(46.67)$ & & \\
\hline No & 59 & $29(49.15)$ & $30(50.85)$ & & \\
\hline Alcoholism & & & & 1.147 & 0.145 \\
\hline Yes & 45 & $25(55.56)$ & $20(44.44)$ & & \\
\hline No & 89 & $45(50.56)$ & $44(49.44)$ & & \\
\hline Exercise habit & & & & 0.675 & 0.454 \\
\hline Yes & 50 & $27(54.00)$ & $23(46.00)$ & & \\
\hline No & 84 & $47(55.95)$ & $37(44.05)$ & & \\
\hline Place of residence & & & & 0.947 & 0.214 \\
\hline City & 88 & $51(57.95)$ & $37(42.05)$ & & \\
\hline Countryside & 46 & $29(63.04)$ & $17(36.96)$ & & \\
\hline Educational level & & & & 0.847 & 0.341 \\
\hline$<$ Senior high school & 73 & $41(53.16)$ & $32(43.84)$ & & \\
\hline$\geq$ Senior high school & 61 & $33(54.10)$ & $28(45.90)$ & & \\
\hline Marital status & & & & 0.547 & 0.647 \\
\hline Married & 125 & $66(52.80)$ & $59(47.20)$ & & \\
\hline Unmarried & 6 & $3(50.00)$ & $3(50.00)$ & & \\
\hline
\end{tabular}

comprised 37 males and 30 females aged 44-65 years, with an average age of $57.60 \pm 5.15$ years. The control group comprised 35 males and 32 females aged of 41-67 years, with an average age of $58.10 \pm 5.13$ years. There were no differences in the basic clinical data such as sex and age between the two groups ( $p>0.05$; Table I). The study was reviewed and approved by the Ethics Committee of the Central Hospital of Wuhan, and all patients and their families were informed and provided signed written informed consent.
Inclusion criteria for the study were: Patients diagnosed with CA by computerized tomography angiography (CTA) and digital subtraction angiography (DSA); patients with no blood relationship to each other; patients with no history of nephrotoxic drugs; patients with no autoimmune diseases of liver cirrhosis, and patients with depression, hypertension, and diabetes.

Exclusion criteria for the study were: Patients with $<6$ months disease; patients with drug treatment; patients 


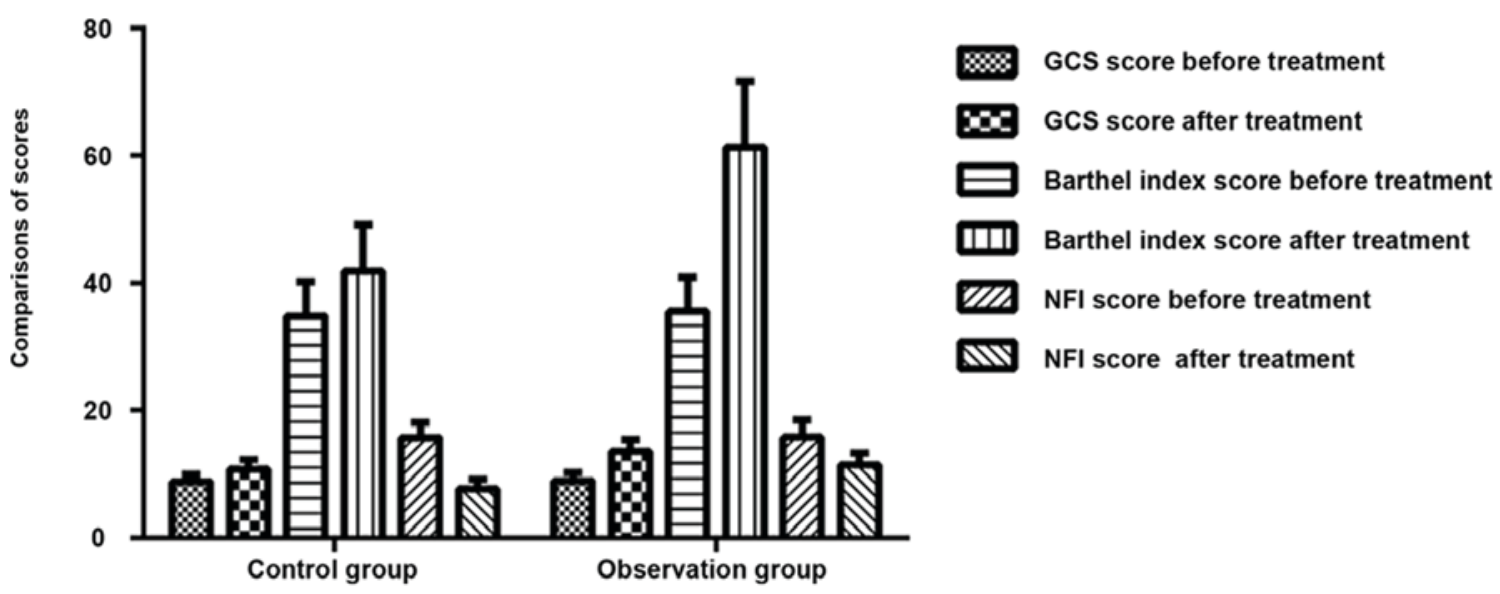

Figure 1. Comparisons of scores between the two groups of patients after treatment. The figure shows that, after treatment, the Barthel index score in the observation group is significantly higher than that in the control group $(\mathrm{p}<0.01)$, and there are statistically significant differences in the GCS and NFI scores between the observation and control groups $(\mathrm{p}<0.05)$. GCS, Glasgow coma scale; NFI, neurological fatigue index

with other genetic diseases; patients without radio-therapy or chemotherapy; patients with autism, memory impairment or hearing impairment; and patients not cooperative with the follow-up or with incomplete clinical information.

Therapeutic regimens. The two groups of patients received hyperbaric oxygen therapy after embolization of CA [pressure in the oxygen chamber: $0.2 \mathrm{mPa}$; 30 -min oxygen $(99.50 \%)$ inhaling twice at $20 \mathrm{~min}$ after boosting; air inhaling for $5 \mathrm{~min}$ in the normal pressure chamber; and $20 \mathrm{~min}$ after decompression, the normal level was restored]. The control group was administered vitamin B6 tablets (specifications: $10 \mathrm{mg}$, GUOYAOZHUNZI H20055305; Shanhaidan Pharmaceutical Co., Ltd.; Shaanxi Pharmaceutical Holding Group Company, Shaanxi, China) by swallowing with warm water, 5 tablets/day, once a day. The observation group was given glycerol and fructose injection (specifications: $250 \mathrm{ml}$, YAOZHUNZI H20046028; Foshan Shuanghe Pharmaceutical Co., Ltd., Shuanghe, China) based on the treatment in the control group, who received $250 \mathrm{ml}$ for every $24 \mathrm{~h}$. The two groups of patients were treated for 14 days.

Observation indexes. The consciousness and mental state of patients were graded by the Glasgow coma scale (GCS) score, In addition, Doppler ultrasound and German Siemens Color Doppler ultrasound instruments were used to detect the mean flow velocity of cerebral artery of the patients. The daily life status of the patients was graded by the Barthel index score, and the neurological fatigue index (NFI) score was used to evaluate the neurological impairment of the patients.

Statistical analysis. In the present study, SPSS 22.0 (IBM Corp., Armonk, NY, USA), supported by Beijing Sichuang Weida Information Technology Co., Ltd., Beijing, China, was used to analyze the collected data. The measurement data were expressed as mean $\pm \mathrm{SD}$ and Chi-square test was used for comparisons between the two groups, Finally, the least significant difference (LSD) test was used for pairwise comparisons. $\mathrm{P}<0.05$ was considered to indicate a statistically significant difference.
Table II. Comparisons of the mean flow velocity of MCA in two groups of patients before and after treatment.

\begin{tabular}{lcc}
\hline Groups & Before treatment & After treatment \\
\hline Control & $107.14 \pm 23.84$ & $123.14 \pm 25.67^{\mathrm{a}}$ \\
Observation & $108.41 \pm 22.14$ & $140.31 \pm 35.41^{\mathrm{a}}$ \\
P-value & $>0.05$ & $<0.05$ \\
\hline
\end{tabular}

Compared with that before treatment $\left({ }^{\mathrm{a}} \mathrm{p}<0.05\right)$. MCA, middle cerebral artery.

\section{Results}

Comparisons of scores of the two groups of patients after treatment. The GCS score of patients in the observation group after treatment $(13.54 \pm 1.87)$ was different from that in the control group $(10.67 \pm 1.48)(\mathrm{p}<0.05)$. The Barthel index score in the observation group $(61.33 \pm 10.31)$ was significantly different from that in the control group $(41.77 \pm 7.34)(\mathrm{p}<0.01)$. The NFI score showed that there was a difference between the control group $(7.64 \pm 1.47)$ and the observation group $(11.41 \pm 1.84)(\mathrm{p}<0.05$; Fig. 1).

Comparisons of the mean flow velocity of middle cerebral artery (MCA) in the two groups of patients before and after treatment. The mean flow velocity of MCA in the observation group after treatment $(140.31 \pm 35.41)$ was significantly different from that in the control group $(123.14 \pm 25.67)(\mathrm{p}<0.05)$, and there was no significant difference compared with that before treatment in the control group ( $p>0.05$; Table II).

Incidence rate of prognostic complications in patients. Comparisons of the incidence rate of postoperative complications between the two groups of patients showed that the incidence rates of postoperative cerebral vasospasm (1.49\%), cerebral ischemia $(1.49 \%)$, hematoma at puncture site $(2.98 \%)$, and aneurysm rupture and hemorrhage (4.47\%) in the observation group were lower than those of cerebral vasospasm (8.95\%), 
Table III. Incidence of prognostic complications in patients.

\begin{tabular}{lcccc} 
Groups & Cerebral vasospasm & Cerebral ischemia & Hematoma at puncture site & $\begin{array}{c}\text { Aneurysm rupture and } \\
\text { hemorrhage }\end{array}$ \\
\hline Observation & $1(1.49 \%)$ & $1(1.49 \%)$ & $2(2.98 \%)$ & $3(4.47 \%)$ \\
Control & $6(8.95 \%)$ & $5(7.46 \%)$ & $6(8.95 \%)$ & $7(10.44 \%)$ \\
P-value & $<0.05$ & $<0.05$ & $<0.05$ & $<0.05$ \\
\hline
\end{tabular}

cerebral ischemia (7.46\%), hematoma at puncture site (8.95\%), and aneurysm rupture and hemorrhage (10.44\%) in the control group, and the differences were statistically significant $(\mathrm{p}<0.05$; Table III).

\section{Discussion}

The disability and mortality rates of hemorrhage caused by rupture of CA are very high. There are data indicating that nearly $30 \%$ of aneurysm patients eventually succumbed to subarachnoid hemorrhage, and nearly half of the patients had permanent neurological deficits (10). Embolization of CA is currently the most effective treatment, but there are more postoperative complications, such as cerebral vasospasm, hydrocephalus and delayed cerebral ischemia. In particular, cerebral vasospasm is the main cause of the high disability and mortality rates caused by embolization of CA. The clinical manifestations of CA include unconsciousness, limb paralysis, neurolocation dysfunction, and high fever headache, whose CT detection is mainly manifested as abnormal lumen morphology with skull base artery continuous contraction (11).

Glycerol fructose is a kind of high permeability dehydration compound preparation, which can improve the intravascular osmotic pressure and cause dehydration, thereby relieving the brain edema in patients. As it is a mixed preparation, its osmotic pressure is 7-fold higher than that of the human body by (12). Glycerol fructose can increase the plasticity of red blood cells, resulting in increased oxygen supply and vascular reflex contraction, and ultimately promote the reduction of edema (13). In addition, glycerol fructose is decomposed into $\mathrm{H}_{2} \mathrm{O}$ and $\mathrm{CO}_{2}$ providing energy for the human body, and since it is not metabolised in the kidney, no damage occurs (14). Moreover, vitamin B6, otherwise known as pyridoxine, is crucial in the metabolism of the body, as well as in the developmental and functional regulation of the healthy nervous system $(15,16)$. A study has shown (17) that vitamin B6 can reduce the concentration of hemocyanins (Hcys) in patients (increase of Hcy may indicate the occurrence of other cardiovascular diseases such as atherosclerosis) and platelet aggregation, because vitamin B6 is involved in the reaction of enzymes to prevent atherosclerosis.

In this study, the recovery of patients with $\mathrm{CA}$ receiving glycerol fructose combined with vitamin B6 treatment was observed. The scores in each group were evaluated, and it was found that, in GCS, Barthel, and NFI scores, the disease condition of patients in each group was significantly improved after treatment compared with that before treatment, and there was a statistical difference $(p<0.05)$. There was a significant difference in the Barthel score between the observation and control groups $(\mathrm{p}<0.01)$, indicating that glycerol fructose combined with vitamin B6 is a major contributor in the daily life and action of patients after embolization of CA. The mean flow velocity of MCA was detected and compared, and results showed a significant increase after treatment. However, the mean flow velocity of MCA in the control group increased more gradually than that in the observation group, and the difference was statistically significant $(\mathrm{p}<0.05)$. This result suggested that the combination of glycerol fructose and vitamin B6 can improve the mean flow velocity of MCA of patients, and that it is beneficial to the recovery of patients. Finally, the postoperative complications of patients were counted, and it was found that the incidence rate of postoperative complications of patients in the control group was higher than that in the observation group, and the difference was statistically significant $(\mathrm{p}<0.05)$, indicating that the combination of the two drugs can reduce the incidence rate of postoperative complications. Previous findings have shown that vitamin $\mathrm{B} 6$ can promote the synthesis of endogenous carbon monoxide (NO) and platelet-derived NO (18-20). However, endogenous NO and platelet-derived NO can reduce platelet activation and platelet aggregation, thereby indicating that vitamin B6 can indirectly affect platelet activation and platelet aggregation, and reduce the occurrence of atherosclerosis.

There are also some limitations to this study. It is currently not known whether the number of specimens and the regional differences have an impact on this study. In future research, the results need to be improved using a larger sample.

In conclusion, glycerol fructose combined with vitamin B6 in the postoperative treatment of patients with CA was examined in this study. It was found that the combination of the two drugs can reduce the incidence rate of postoperative complications of patients and improve their quality of life. Therefore, it is beneficial to recovery and it is worthy of clinical promotion.

\section{Acknowledgements}

Not applicable.

\section{Funding}

Not applicable.

\section{Availability of data and materials}

The datasets used and/or analyzed during the present study are available from the corresponding author on reasonable request. 


\section{Authors' contributions}

$\mathrm{XC}$ wrote the manuscript, designed the methods and the idea of this study, and rewied the study. XC and TL analysed, discused and collected the data, and followed up management of the patients. All authors read and approved the final manuscript.

\section{Ethics approval and consent to participate}

This study was approved by the Ethics Committee of the Central Hospital of Wuhan (Wuhan, China). Signed written informed consents were obtained from the patients and/or guardians.

\section{Consent for publication}

Not applicable.

\section{Competing interests}

The authors declare that they have no competing interests.

\section{References}

1. Chalouhi N, Hoh BL and Hasan D: Review of cerebral aneurysm formation, growth, and rupture. Stroke 44: 3613-3622, 2013.

2. Starke RM, Chalouhi N, Ding D, Raper DM, Mckisic MS Owens GK, Hasan DM, Medel R and Dumont AS: Vascular smooth muscle cells in cerebral aneurysm pathogenesis. Transl Stroke Res 5: 338-346, 2014.

3. Skodvin TØ, Johnsen LH, Gjertsen $\varnothing$, Isaksen JG and Sorteberg A: Cerebral aneurysm morphology before and after rupture: Nationwide case series of 29 aneurysms. Stroke 48: 880-886, 2017.

4. Aldakkan A, Mansouri A, Jaja BN, Alotaibi NM and Macdonald RL; Subarachnoid Hemorrhage International Trialists Collaborators: Predictors of delayed cerebral ischemia in patients with aneurysmal subarachnoid hemorrhage with asymptomatic angiographic vasospasm on admission. World World Neurosurg 97: 199-204, 2017.

5. Chen M: A checklist for cerebral aneurysm embolization complications. J Neurointerv Surg 5: 20-27, 2013.

6. Brinjikji W, Lanzino G, Cloft HJ, Siddiqui AH, Boccardi E, Cekirge S, Fiorella D, Hanel R, Jabbour P, Levy E, et al: Risk factors for ischemic complications following pipeline embolization device treatment of intracranial aneurysms: Results from the IntrePED study. AJNR Am J Neuroradiol 37: 1673-1678, 2016.

7. Delgado Almandoz JE, Crandall BM, Scholz JM, Fease JL, Anderson RE, Kadkhodayan Y and Tubman DE: Last-recorded $\mathrm{P} 2 \mathrm{Y} 12$ reaction units value is strongly associated with thromboembolic and hemorrhagic complications occurring up to 6 months after treatment in patients with cerebral aneurysms treated with the pipeline embolization device. AJNR Am J Neuroradiol 35 $128-135,2014$.
8. Pantophlet AJ, Gilbert MS, van den Borne JJGC, Gerrits WJ, Roelofsen H, Priebe MG and Vonk RJ: Lactose in milk replacer can partly be replaced by glucose, fructose, or glycerol without affecting insulin sensitivity in veal calves. J Dairy Sci 99: 3072-3080, 2016.

9. Masoumi SZ, Ataollahi M and Oshvandi K: Effect of combined use of calcium and vitamin B6 on premenstrual syndrome symptoms: A Randomized Clinical Trial. J Caring Sci 5: 67-73, 2016.

10. Singh N, Hopkins SJ, Hulme S, Galea JP, Hoadley M, Vail A, Hutchinson PJ, Grainger S, Rothwell NJ, King AT, et al: Critical role of TNF- $\alpha$ in cerebral aneurysm formation and progression to rupture. J Neuroinflammation 11: 2014. doi: 10.1186/1742-2094-11-1.

11. Yoshimura Y, Murakami Y, Saitoh M, Yokoi T, Aoki T, Miura K, Ueshima H and Nozaki K; SSS Research Group: Statin use and risk of cerebral aneurysm rupture: A hospital-based case-control study in Japan. J Stroke Cerebrovasc Dis 23: 343-348, 2014.

12. Macdonald I, Keyser A and Pacy D: Some effects, in man, of varying the load of glucose, sucrose, fructose, or sorbitol on various metabolites in blood. Am J Clin Nutr 31: 1305-1311, 1978.

13. Softic S, Gupta MK, Wang GX, Fujisaka S, O'Neill BT, Rao TN, Willoughby J, Harbison C, Fitzgerald $\mathrm{K}$, Ilkayeva $\mathrm{O}$, et al: Divergent effects of glucose and fructose on hepatic lipogenesis and insulin signaling. J Clin Invest 127: 4059-4074, 2017.

14. Tsubokawa T, Katayama Y and Ishii S: Fructose-added glycerol (Glyceol) for therapy of elevated intracranial pressure: Analysis of the side effects of long-term administration in a multi-institutional trial. Neurol Res 11: 249-252, 1989.

15. Wisam D, Nathan M, Juliette R and Yves B: Role of vitamin B6 in idiopathic burning mouth syndrome: Some clinical observations. J Biol Buccale 23: 77-83, 2016.

16. Stouder CE, Warren KJ, Perdue OF, Stewart AL, Padgett CW, Amonette AJ and Saha A: Synthesis, characterization, computational study, and biological relevance of a family of isostructural, mononuclear $\mathrm{Ln}(\mathrm{Ln}=\mathrm{Gd}, \mathrm{Tb}, \mathrm{Dy}, \mathrm{Ho}, \mathrm{Er})$ complexes containing pyridoxine, an essential ingredient of vitamin B6 enzyme. Inorg Chim Acta 464: 172-181, 2017.

17. Hofmann MA, Lalla E, Lu Y, Gleason MR, Wolf BM, Tanji N, Ferran LJ Jr, Kohl B, Rao V, Kisiel W, et al: Hyperhomocysteinemia enhances vascular inflammation and accelerates atherosclerosis in a murine model. J Clin Invest 107: 675-683, 2001.

18. Wu Y, Liu Y, Han Y, Cui B, Mi Q, Huang Y, Wang L, Jiang Q, Chen Q, Liu N, et al: Pyridoxine increases nitric oxide biosynthesis in human platelets. Int J Vitam Nutr Res 79: 95-103, 2009.

19. Gkaliagkousi E, Ritter J and Ferro A: Platelet-derived nitric oxide signaling and regulation. Circ Res 101: 654-662, 2007.

20. Rosenberg J, Ischebeck T and Commichau FM: Vitamin B6 metabolism in microbes and approaches for fermentative production. Biotechnol Adv 35: 31-40, 2017.

(i) $(5)$ This work is licensed under a Creative Commons Attribution-NonCommercial-NoDerivatives 4.0 International (CC BY-NC-ND 4.0) License. 